\title{
MEDIA-BASED STRATEGIES TO REDUCE RACIAL STEREOTYPES ACTIVATED BY NEWS STORIES
}

\section{By Srividya Ramasubramanian}

This study focuses on the role of media in facilitating and inhibiting the accessibility of stereotypes primed by race-related news stories. Specifically, it examines experimentally the effects of two strategies for reducing stereotype accessibility: an audience-centered approach that explicitly instructs audiences to be critical media consumers, a goal of media literacy training; and a message-centered approach using stereotype-disconfirming, counter-stereotypical news stories. Participants viewed either a literacy or control video before reading stereotypical or counter-stereotypical news stories about African Americans or Asian Indians. Implicit stereotypes were measured using response latencies to hostile and benevolent stereotypical words in a lexical decision task. Results suggest that a combination of audience-centered and messagecentered approaches may reduce racial stereotypes activated by news stories.

Descriptive studies provide overwhelming evidence that a few long-standing stereotypes portray racial minorities in the media. ${ }^{1}$ Research of depictions of African Americans in the media reveals that portrayals of this group as criminal, aggressive, and unintelligent help reinforce and maintain hostile anti-black prejudice. ${ }^{2}$ Asian Americans in the news and entertainment media have depictions of seemingly positive stereotypes of "model minorities" who are non-controversial, polite, hard-working people who do not raise their voices against the existing system. ${ }^{3}$ Similar observable biases in the Western media portray thirdworld peoples as naive, inferior, traditional, and uncivilized, thus rationalizing perpetuation of benevolent, paternalistic prejudice toward these ethnic groups."

Because racial stereotypes in the media serve to justify, reinforce, and perpetuate hostile and benevolent racism, focused research effort on strategies to undermine and eventually eliminate stereotypes is important. Stereotypes are created and altered based on first-hand experiences with members of stigmatized groups and second-hand information from sources such as mass media, friends, and family. Although both direct and indirect sources of stereotype reduction are acknowledged, the bulk

Srividya Ramasubramanian is an assistant professor in the Department of Communication at Texas A\&M University. The author would like to thank Mary Beth Oliver, Travis Dixon, and Mike Stephenson for their valuable feedback on earlier drafts of this paper.

JEMC Quarterly

Vol. 84 No. 2 Summer 2007 249-264 O2007 AEMC 
of the scholarship on inter-group relations has focused on direct observations of stereotyping behaviors in interpersonal settings. However, considering people form stereotypes even with minimal or no direct contact, the role of vicarious contact through mass media in activating and modifying existing stereotypes becomes an important consideration. ${ }^{6}$

In comparison to descriptive research on media stereotypes, studies that explain the cognitive processes involved in media stereotyping are relatively few. Rarer still are studies within fields of mass communication and journalism that focus on stereotype and prejudice reduction. The current project takes a step toward filling this gap in the literature by examining the effectiveness of media-based interventions that mitigate the damaging effects of biased news stories about African Americans and Asian Indians. The study employs two strategies: (1) an audience-based approach that explicitly instructs audiences how to be critical media consumers, and (2) a message-based approach, which provides participants with counter-stereotypical news stories that disconfirm existing cultural stereotypes about racial groups. The effects of these two media-based techniques on the accessibility of hostile and benevolent racial stereotypes are considered.

Stereotype Accessibility. Before factors that influence stereotype reduction are examined, an understanding of the cognitive processes involved during stereotyping is necessary. Recent research explains that the stereotyping process has two stages: (1) stereotype activation that is more automatic, and (2) stereotype application that is more deliberate. ${ }^{7}$ In other words, stereotypical thoughts about out-groups are readily activat$e d$ at the implicit level even though they are not applied consciously at the explicit level. ${ }^{8}$ Implicit stereotypes seem to be beyond an individual's control, are a subconscious process, and require little or no mental effort. ${ }^{9}$

Reaction time measures or response latencies are often the common measures of stereotype accessibility. When researchers have asked participants if a given feature is characteristic of a particular group, the speed of response becomes an indicator of the strength of association and ease of accessibility of the stereotypes. Word-stimuli consistent with existing stereotypes of a particular group are likely to be processed faster than those that are inconsistent. ${ }^{10}$ Implicit measures of stereotypes, such as lexical decision tasks, help overcome problems such as reactivity and social desirability issues encountered while measuring racism using self-reported attitudinal scales. Moreover, reaction time measures are able to access non-conscious associations, activated automatically without the participants' awareness. Studies have shown that participants with accessible attitudes are faster in recognizing stereotypical words. ${ }^{11}$ The underlying assumption is that information, stored in memory, forms associative networks of related constructs. Participants will be faster in performing tasks that involve constructs closely associated with one another as compared to unrelated ones.

In order to bring about lasting prejudice reduction, simply suppressing the application of stereotypes in interpersonal situations is insufficient. Providing media consumers with the tools to reduce the activa- 
tion of stereotypes in the first place adds a valuable dimension. Stereotype activation is, understandably, more difficult to reduce than stereotype application. Whether or not people are thought to be able to suppress implicit stereotypes depends heavily on understanding how automatic or malleable stereotypical attitudes are. Therefore, media scholars interested in bringing about stereotype reduction should focus on the factors that reduce stereotype accessibility at the subconscious, implicit level.

Recent studies suggest that although implicit stereotype activation is quite unintentional and unconscious, perhaps it is controllable under certain circumstances. ${ }^{12}$ The Fiske and Neuberg continuum model explains that unless the perceiver has the motivation to be accurate in making judgments, automatic stereotype processing will be the preferred mode in comparison to deliberate, individuated processing. ${ }^{13}$ While stereotypical processing of information is almost entirely social categorization-based, the individuated processing route involves an examination of the attributes of the specific person being evaluated before making a judgment. That is, unless motivational reasons to be accurate exist, people will be likely to simply use activated stereotypes in forming impressions. However, even when people wish to use the mental effort to control their implicit stereotypes, they can do so only if they have the cognitive resources available for such processing. ${ }^{14}$ Other researchers have identified factors such as social norms, focus of attention, and nature of stimulus cues as factors that determine the extent to which stereotype accessibility can be reduced. ${ }^{15}$

Role of Media in Stereotype Activation. Due to the ubiquitous nature of media stereotypes, biased information inevitably becomes incorporated into "common knowledge" or schemata that viewers form about stereotyped groups. According to the neo-associationistic model of media priming, when such cognitive networks are firmly in place, exposure to media stereotypes can serve as cognitive shortcuts to immediately and easily activate the cultural stereotypes associated with the group. ${ }^{16}$ For instance, seeing a local news report about an African American criminal suspect might automatically activate stereotypes of aggression and troublesomeness. Watching a stand-up comedian joke about an Asian American might summon thoughts of slyness and lack of warmth typically associated with this group. Watching a documentary film about the economic struggle of a family in a third-world country might invoke ascribed traits such as uncivil and impoverished.

Likewise, the activation-recency hypothesis proffered by Hansen and Hansen suggested that prolonged exposure to biased media content makes these notions highly automatic. ${ }^{17}$ Thus, without conscious efforts to rectify, recently activated primes will bias evaluations in subsequent tasks that immediately follow exposure to stereotype content. Frequently and recently used stereotypes are more easily accessible for making judgments about relevant target groups. Such activated stereotypes have been known to implicitly influence perceivers' social judgments and impressions about the racial group even without conscious awareness. ${ }^{18}$ 
The effects of stereotypical media primes on judgments have been demonstrated in many different media contexts. For example, Givens and Monahan found that after viewing movie clips depicting African American women in stereotypical roles, participants responded faster to negative words than positive words in a reaction-time task. ${ }^{19}$ On further analysis, they also noted that when specific stereotypical roles, such as the jezebel stereotype, were primed, words associated with a particular stereotypical schema were recognized more quickly than those inconsistent with the primed stereotype.

Media-based Strategies for Stereotype Reduction. Broadly, in the context of mediated communication, two media-based strategies constitute the methods for diminishing the harmful effects of negative media content. The first is an audience-centered approach in which people receive instructions to consciously negate effects by critical reflection of media messages during or prior to exposure to such content. The second is a message-centered approach where audiences receive no specific, direct instructions to negate media stereotypes, but simply confront counter-stereotypical, stereotype-disconfirming media content.

Audience-centered Approach to Stereotype Reduction. An audiencecentered approach focuses on instructing participants to expend conscious effort to reduce stereotype accessibility while viewing biased media materials. Specifically, media literacy training helps audiences read news stories critically by observing how news media often serve to rationalize existing social norms and expectations. The assumption is that when media consumers become more conscious of the role of media in actively shaping social reality, they will be less likely to be influenced by the biased, unidimensional portrayals of racial groups in the media.

Media literacy has been conceptualized as "discriminating responsiveness" to media such that viewers question what they see or read in the media. ${ }^{20}$ The current study uses the more recent conceptualization of media literacy by Scharrer, who defined it as something that "helps foster critical thinking and discussion of media-related issues, including how media messages are created, marketed, and distributed as well as their potential influence (or how they are received)." ${ }^{21}$ From this perspective, the goal of media literacy training is to help counter the negative effects of media content. ${ }^{22}$ This approach follows the Fiske and Neuberg continuum model, suggesting that if people have the motivation to be accurate and have cognitive resources available, they will likely use deliberative, individuating information, suppressing implicit stereotyping processes. ${ }^{23}$

Some research studies show that explicit instructions from experts to negate stereotypes can have a positive influence on reducing stereotyping effects. ${ }^{24}$ For example, Kawakami and colleagues trained participants extensively to negate stereotypical associations by saying "yes" in their minds when encountering neutral exemplars, and "no" when encountering stereotypical exemplars. ${ }^{25}$ These experimenters concluded that implicit stereotypes can be reduced with practice and conscious effort. However, none of these studies focused on using media literacy training in the context of racial stereotype reduction. 
Message-centered Approach to Stereotype Reduction. Another more indirect way to encourage stereotype mitigation is to present participants with information that contradicts existing stereotypes. Counterstereotypical exemplars appear to have an impact on not only stereotype activation, but also on stereotype reduction. Even people who use schema-like cognitive abstractions of out-groups may be likely to lessen their stereotypes when they encounter stereotype-disconfirming information in the form of counter-exemplars. ${ }^{26}$ According to the conversion model, exposure to extreme counter-exemplars suddenly, abruptly, and completely changes perceivers' attitudes. On the other hand, the bookkeeping model assumes a very rational perceiver who keeps a mental tally of stereotypical-confirming and stereotypedisconfirming information. In contrast, the sub-typing model suggests that perceivers will treat counter-stereotypes as exceptions and create subtypes in such a way that the actual stereotype itself remains intact.

For example, with exposure to counter-stereotypical media exemplars of admirable members of stigmatized groups, participants express increased sympathy toward the stigmatized group..$^{27}$ Observable examples of such effects of stereotype-disconfirming stories occurred only if positive feelings toward a celebrity existed with disregard for the atypical nature of the exemplars. Otherwise, a tendency arose for information disconfirming stereotypical expectations to be discounted such that the original stereotype remained unchanged. In other studies, counterstereotypical exemplars centered on "ordinary" non-celebrity people were also effective in improving attitudes toward stigmatized groups. ${ }^{2 B}$

The present study operationalizes counter-stereotypes as news stories focusing on non-celebrity members of racial minority groups that disconfirm existing cultural stereotypes by exemplifying the opposite of stereotypical traits commonly associated with the featured racial group.

Based on the literature discussed thus far, mitigation of the harmful effects of media stereotypes is possible by influencing perceivers' motivations to be accurate through use of media literacy instructions and the presence of stimulus cues such as stereotype-disconfirming information from counter-stereotypical news stories. The present study applies these routes to stereotype attenuation in the context of mass communication by testing the effects of two media-based strategies for inhibiting accessibility to racial stereotypes activated by reading news stories about African Americans and Asian Indians. The examination concerns how (1) media literacy instruction for being reflective creates critical media consumers, and (2) exposure to counterstereotypical media exemplars influences the speed of recognition of hostile and benevolent stereotypical words. This study explores the following hypotheses:

H1: Participants who watch the literacy video, as compared to the control video, will be slower in recognizing benevolent stereotypical words, especially after reading sto- 
ries relating to Asian Indians as compared to those about African Americans. However, such effects will be stronger for those who read counter-stereotypical news stories than those who read stereotypical news stories.

H2: Participants who watch the literacy video, as compared to the control video, will be slower in recognizing hostile stereotypical words, especially after reading stories relating to African Americans as compared to those about Asian Indians. However, such effects will be stronger for those who read counter-stereotypical news stories than those who read stereotypical news stories.

\section{Method}

Overview. Caucasian-American undergraduate communication students $(N=158)$, almost equally divided between male and female, in a large northeastern U.S. university participated in a 2 (Type of Video: literacy or control) X 2 (Stereotypicality of News Story: stereotypical or counter-stereotypical) X 2 (Racial Group Depicted in Story: African Americans or Asian Indians) factorial experiment. Participants were randomly assigned to either the literacy or control video condition. After viewing the video, participants, by random assignment, read either stereotypical or counter-stereotypical stories about African Americans or Asian Indians. Following this task, participants completed a computer-based lexical decision task that measured the speed of recognition of hostile and benevolent stereotypical word-stimuli.

Procedure. The information participants received about the exercise was that they would take part in two studies-one study on news and another on judgment and memory. The first mini-study, called the news study, consisted of an experimental session of about thirty minutes. Administration of this part of the session included the media literacy (or equivalent control) instruction. Participants saw either a media literacy video or a control video for about twelve minutes, after which they applied the information from the video to analyze news stories.

Immediately at the end of the video, participants summarized the main points of the video. Keeping the contents of the video in mind, they next analyzed five news stories. Participants had about three minutes to read and summarize the key points of each of the stories. Depending on the experimental condition, the second and fifth news stories were stereotypical about African Americans, stereotypical about Asian Indians, counter-stereotypical about African Americans, or counter-stereotypical about Asian Indians.

In the latter half of the session, participants took part in a judgment and memory study in which they completed a lexical decision task. This exercise consisted of briefly appearing series of letter strings which had to be recognized as a word or non-word. This part of the experimental session used the speed of recognition of stereotypical words as a measure for the level of implicit racial stereotypes, such that lower speeds of recognition indicated lesser stereotype activation. 


\section{Stimuli.}

Video Intervention. The literacy video had comments on media education from experts who introduced participants to some key basic concepts about media literacy, harmful effects of media, critical viewing skills, and strategies that viewers could use to avoid making generalizations based on biased media exemplars. In contrast, the control video, unrelated to media literacy, focused instead on various writing styles used in the news media such as hard news, feature writing, etc. Both these videos, created by editing scenes from existing media-related video resources, included interviews with experts relevant to the video's subject. The same people appeared for the interviews in both the videos with the same setting.

News Stories. The stereotypical stories selected for African Americans were on violence and unomployment. Correspondingly, those in the African American counter-stereotypical condition read stories about gentleness and entrepreneurial success. Similarly, participants in the stereotypical Asian Indian condition read stories about tradition and poverty, whereas those in the counter-stereotypical Asian Indian condition read stories about modernity and wealth.

The news stories were edited and modified versions of existing news articles. All of the stories featured narratives about an individual from the racial group exemplifying the associated stereotype or the counter-stereotype. Manipulation of the stories maintained uniformity in length and format across different conditions. The story formats included columns, with headlines and by-lines, to make them appear similar to any typical news article. All stories were approximately half a page in length. Open-ended questions, related to participants' comprehension of each news story, were presented after each news story.

Pre-testing of Stimuli. As a check of manipulation effectiveness, a pre-test was conducted with 68 undergraduate students not participating in the final experiment. In accordance with the intended manipulation, the literacy video was significantly more educative $(M=5.35$ : $\mathrm{sd}=$ 1.26) than the control video $(M=4.47 ; \mathrm{sd}=1.48), t(65)=-2.53 ; p<.05$, and, significantly more thought-provoking $(M=4.86$; sd $=1.53)$ than the control video $(M=3.42 ; \mathrm{sd}=1.41) ; t(65)=-3.94 ; p<.001$. They were both accepted as equally interesting, clear, and easy to understand. Qualitative feedback also indicated that the messages about stereotype reduction in the literacy video were clearly comprehended.

This pretest included 20 news stories about Asian Indians and African Americans. A 7-point Likert scale rated the extent to which news stories reinforced or challenged cultural stereotypes about the racial group. As a secondary check of manipulation effectiveness, participants also evaluated the extent to which each news story illustrated specific stereotypical or counter-stereotypical traits associated with African Americans and Asian Indians using 7-point semantic differential scales with bipolar adjectives such as traditional-modern and aggressive-peaceful. Stories selected for the final study were those determined to be most stereotypical and most counter-stereotypical about African Americans and Asian Indians. 


\section{TABLE 1}

Type of Video Seen X Racial Group Depicted in News Story X Stereotypicality of News Story: Interaction Effects on Reaction Times in Milliseconds for Benevolent Stereotypes

\begin{tabular}{llcrr}
$\begin{array}{l}\text { Racial Group } \\
\text { Depicted in } \\
\text { News Story }\end{array}$ & $\begin{array}{l}\text { Stereotypicality } \\
\text { of News Story }\end{array}$ & & \multicolumn{2}{c}{$\begin{array}{c}\text { Reaction Time in Milliseconds } \\
\text { Type of Video Seen }\end{array}$} \\
\hline Stories about & Stereotypical & $M$ & Control & Literacy \\
African & Counter- & $M$ & $640.54 \mathrm{a}$ & 613.79 a \\
Americans & stereotypical & $S E$ & 1.04 & 1.04 \\
& & & $561.52^{\mathrm{b}}$ & $634.56 \mathrm{a}$ \\
Stories about & Stereotypical & $M$ & 1.04 & 1.04 \\
Asian & & $S E$ & $621.80_{\mathrm{a}}$ & $617.73 \mathrm{a}$ \\
Indians & Counter- & $M$ & 1.04 & 1.04 \\
& stereotypical & $S E$ & $597.07 \mathrm{a}$ & $554.95 \mathrm{a}$ \\
& & & 1.04 & 1.04
\end{tabular}

$F(1,150)=4.73 ; p=.03 ;$ partial $\eta^{2}=.03$.

Note: Means in the same row with no common lowercase subscript differ at $p<.05$ using Holms sequential Bonferroni post hoc comparisons.

Dependent Measure: Response Latencies. The recorded response time for participants in the lexical decision task was a measure of implicit stereotype activation. ${ }^{29}$ Participants received the target stimulus, which was either a word (e.g., smart) or a non-word (e.g., tinpy). All non-words had lengths matching words. Participants had to decide as quickly and accurately as possible whether the target stimulus was a word or nonword by using the appropriate response keys on the computer keyboard.

The first round in this task was a practice session where participants received feedback on their performances. Here, 24 target stimuli (words or non-words) appeared in quick succession in random order. An exclamation point preceded each target stimulus for $\mathbf{3 0 0}$ milliseconds. Twelve of these stimuli were neutral words (e.g., after, complete, more) unrelated to stereotypes. The remaining stimuli were non-words of equal length.

Once the practice round ended, 72 target stimuli appeared in a random order. Of these, 16 stimuli were stereotypical words (e.g., lazy, spiritual, poor) based on pre-tests. The remaining 48 stimuli equally presented neutral words (e.g., lady, delicious, pour) and non-words (e.g., linr, foigpnafe, pkid) of length equal to the stereotypical words. Of the stereotypical words, some related to benevolent stereotypes (e.g., traditional, polite) and some related to hostile stereotypes (e.g., lazy, uneducated). An output file for each participant recorded the speed of response to each stimulus in milliseconds.

Results

The focus of the statistical analyses is on the effects of the type of news stories and media literacy instruction on participants' speed of 


\section{TABLE 2}

Type of Video Seen X Racial Group Depicted in News Story X Stereotypicality of News Story: Interaction Effects on Reaction Times in Milliseconds for Hostile Stereotypes

\begin{tabular}{|c|c|c|c|c|}
\hline \multirow{2}{*}{$\begin{array}{l}\text { Racial Group } \\
\text { Depicted in } \\
\text { News Story }\end{array}$} & \multirow{2}{*}{$\begin{array}{l}\text { Stereotypicality } \\
\text { of News Story }\end{array}$} & & \multicolumn{2}{|c|}{$\begin{array}{c}\text { Reaction Time in Milliseconds } \\
\text { Type of Video Seen }\end{array}$} \\
\hline & & & \multirow{2}{*}{$\frac{\text { Control }}{660.50}$} & \multirow{2}{*}{$\begin{array}{r}\text { Literacy } \\
613.61\end{array}$} \\
\hline Stories about & Stereotypical & $M$ & & \\
\hline African & & $S E$ & 1.04 & 1.04 \\
\hline \multirow[t]{2}{*}{ Americans } & Counter- & $M$ & $613.41_{b}$ & 678.23 . \\
\hline & stereotypical & $S E$ & 1.04 & 1.04 \\
\hline Stories about & Stereotypical & $M$ & $649.35 \mathrm{a}$ & 604.01 . \\
\hline Asian & & $S E$ & 1.04 & 1.04 \\
\hline \multirow[t]{2}{*}{ Indians } & Counter- & $M$ & $614.63 \mathrm{a}$ & 563.92 \\
\hline & stereotypical & $S E$ & 1.04 & 1.04 \\
\hline
\end{tabular}

Note: Means in the same row with no common lowercase subscript differ at $p<.05$ using Holms sequential Bonferroni post hoc comparisons.

recognition of hostile and benevolent stereotypical word-stimuli. A 2 (Stereotypicality of News Story) X 2 (Type of Video Seen) X 2 (Racial Group Depicted in News Story) ANOVA was conducted.

$\mathrm{H1}$, involving the speed of recognition of benevolent stereotypical word-stimuli, had partial support. As Table 1 illustrates, an interaction effect appeared: among participants who read counter-stereotypical stories about African Americans, those who responded in the literacy video condition $(M=634.56 ; S E=1.04)$ were significantly slower than those who responded in the control video condition $(M=561.52 ; S E=$ $1.04)$ in recognizing benevolent stereotypical word-stimuli; $F(1,150)=$ 4.73; $p \leq .05$; partial $\eta^{2}=.03$. Additionally, a main effect for "Stereotypicality of News Story" was observed but the above-mentioned interaction effect provided a more comprehensive understanding of the results of this analysis. No other main effects or interaction effects were observed.

H2, involving speed of recognition of hostile stereotypical word-stimuli, had partial support. Table 2 shows an interaction effect similar to the one observed in Table 1: among participants who read counter-stereotypical stories about African Americans, those in the literacy video condition $(M=678.23 ; S E=1.04)$ were slightly slower in recognizing hostile stereotypical word-stimuli when compared to those in the control video condition $(M=613.41 ; S E=1.04) ; F(1,150)=2.88$; $p \leq .10$; partial $\eta^{2}=.02$. Although a main effect for "Racial Group Depicted" was observed, the more interesting interaction effects superseded these main effects. No other main effects or interaction effects were observed. 
The findings reveal that activation of implicit racial stereotypes decreases when people receive instruction on critical media literacy skills and gain exposure to stereotype-disconfirming news stories. Apparently, a combination of media-based strategies to reduce accessibility to racial stereotypes at the subconscious level might be more powerful than using any one approach independently. Specifically, with an audience-centered approach that involves media literacy training to reflect critically on media exemplars, participants seem to be more responsive to indirect message-centered strategies, such as exposure to counter-stereotypical information. Activation of both benevolent as well as hostile stereotypes decreased after people who received the media literacy training read stereotype-disconfirming feature stories about African Americans, but similar effects did not appear for news stories that featured Asian Indians.

One possible interpretation of these findings is that people who viewed counter-stereotypical information in the media literacy condition became motivated to suppress their activated stereotypes in order to appear non-prejudiced. Even for a person not overtly prejudiced, negative stereotypes might remain highly accessible because of contextual factors, such as reading about racist incidents in the news and interacting with racist persons in the workplace. Devine's conceptualization of stereotyping suggests that cultural stereotypes are so pervasive in society that their activation is almost inevitable. ${ }^{30}$ These implicit stereotypes might be just as harmful, if not more problematic, as old-fashioned blatant stereotypes because they can influence judgments in subtle, subconscious ways, even among persons who believe that they are not overtly prejudiced. However, on a more optimistic note, the current findings suggest that even the so-called subconscious, automatic process of stereotype activation can respond to motivational factors such as media literacy training and contextual factors such as exposure to counter-stereotypical information. This study contributes to the current debate on the automaticity of implicit attitudes by finding the possibility of suppressing implicit stereotypes when participants proactively seek counter-stereotypical messages and are open to abating stereotypes after being instructed about the harmful effects of media stereotyping.

This explanation is consistent with the limited capacity model of information processing, which suggests that participants who are engaged in more effortful, more systematic information processing rather than default automatic processing are slower to recognize stereotypical word-stimuli. ${ }^{31}$ This is also consistent with the model of stereotype activation and stereotype application provided by Devine and Montieth, which acknowledged that although implicit stereotypes are quite unintentional and perhaps unconsciously activated, the potential exists to control them under certain circumstances. ${ }^{32}$

An alternative interpretation of the findings is that participants who saw the media literacy video and had exposure to counter-stereotypical stories about African Americans were in the condition of having the highest "dosage" of factors designed to motivate participants to alter their existing stereotypes. This explanation lends support to researchers who 
have argued that individual differences in the use of implicit attitudes are due to the ease of stereotype activation by primed social categories rather than a mere lack of motivation to suppress stereotype application. ${ }^{33}$ Participants given instructions about media literacy might be more open to alter their existing cultural stereotypes and replace them with counter-stereotypical information. Driven by the goal to be accurate in their judgments, participants attend to stereotype-disconfirming exemplars more systematically and these recently activated exemplars become readily available in making subsequent evaluations.

Not surprisingly, participants' responses were similar regardless of whether word-stimuli in the lexical decision task were benevolent or hostile stereotypes. This finding supports the argument that both contemptuous and paternalistic stereotypes are two sides of the same coin, reflecting unfavorable attitudes of dominant in-groups toward subordinate out-groups. These findings support research by Glick and Fiske regarding benevolent prejudice in the context of gender stereotypes toward women by expressing positive feelings that are inappropriately patronizing. ${ }^{34}$ Even though the manifestations of this type of prejudice are not negative feelings, they are, nonetheless, hurtful, offensive, and inappropriate from the target's perspective. ${ }^{35}$

Several interpretations may explain the fact that these results were observed for participants who read stories about African Americans but not for those who read stories about Asian Indians. One possibility is that, because African Americans are one of the most visible and prototypical racial minorities in the United States, participants who saw the media literacy video may have interpreted its contents in terms of reduction of prejudice toward African Americans and as inapplicable to any other racial group. That is, the participants who had media literacy training and also read counter-stereotypical news stories about African Americans (but not about Asian Indians) could have made a stronger association between the materials discussed in the media literacy video and the subsequent news stories that were read, leading to greater stereotype suppression.

Another explanation could be that the lesser degree of familiarity and direct contact with Asian Indians, compared to African Americans, could have created more difficulty for generating counter-exemplars for Indians after exposure to media literacy training. Additionally, because Asian Indians may be seen as distant people for Caucasian Americans, lacking inter-dependence or a shared history, compared to African Americans, perhaps stories associated with Asian Indians did not have much personal relevance for Caucasian Americans, making suppression easier. Researchers need to further explore the various characteristics of out-groups that make inhibiting stereotypical traits associated with those groups easier or more difficult.

Because these interpretations are speculative at the moment, further research needs to be conducted to understand the nature of implicit stereotypes. Subsequent studies on this topic would also benefit from examining the possibility of viewer-related characteristics, such as level of prejudice and extent of exposure to news media, which play roles in 
influencing the malleability of implicit racial attitudes. Further studies should examine both implicit and explicit measures of stereotypes in order to distinguish truly sub-conscious automatic processes from controlled conscious processes of stereotyping.

For the most part, the interpretation of the current findings is in terms of suppression of stereotypes. The term "suppression" seems to indicate intentionality that seems rather impossible for a relatively automatic process such as implicit stereotyping. Given that even a brief twelve-minute literacy video and exposure to a few counter-stereotypical news stories were able to reduce stereotype activation, even if such effect was momentary, it is possible that more intense stereotype negation efforts can be successful for altering implicit stereotypical attitudes in order to bring about more permanent stereotype elimination. Future research should look at both the short-term and long-term effects of media literacy and counter-stereotypes from a social cognitive perspective. Although the current study made a special effort to avoid including celebrity exemplars in order to prevent sub-typing effects, news stories did not undergo testing for the extent of their perceived generalization, as a story relating to the entire target group, as opposed to a perception of their being a rather unique, specific story about an individual from the target group. Future studies should manipulate the level of distinctiveness and specificity of the exemplars to test for more specific exemplars leading to greater contrast effects.

Overall, the current study supports the view that, although stereotype activation is apparently largely automatic, the combined effects of media literacy training and exposure to counter-stereotypical media content are likely to reduce stereotype activation. When participants receive training in critical media engagement skills, they are more likely to proactively seek stereotype-disconfirming information in the media, leading to a reduction in the activation of both contemptuous as well as paternalistic stereotypes at the implicit, subconscious level.

\section{NOTES}

1. Robert M. Entman, "Representation and Reality in the Portrayal of Blacks on Network Television News," Journalism Quarterly 71 (fall 1994): 509-20; Robert M. Entman, "Blacks in the News: Television, Modern Racism and Cultural Change," Journalism Quarterly 69 (summer 1992): 341-61; Mary Beth Oliver, "Portrayals of Crime, Race, and Aggression in 'Reality-Based' Police Shows: A Content Analysis," Journal of Broadcasting E Electronic Media 38 (spring 1994): 179-92; Travis L. Dixon and D. Linz, "Overrepresentation and Underrepresentation of African Americans and Latinos as Lawbreakers on Television News," Journal of Communication 50 (spring 2000): 131-54; Dana E. Mastro and Bradley S. Greenberg, "The Portrayal of Racial Minorities on Prime Time Television," Journal of Broadcasting \& Electronic Media 44 (fall 2000): 690-703; Dana E. Mastro and Susannah R. Stern, "Representations of Race in Television Commercials: A Content Analysis of Prime-Time Television," Journal of Broadcasting $\mathcal{E}$ 
Electronic Media 47 (December 2003): 638-47.

2. Travis L. Dixon and Daniel G. Linz, "Race and the Misrepresentation of Victimization on Local Television News," Communication Research 27 (October 2000): 547-73; Mary Beth Oliver, "Caucasian Viewers' Memory of Black and White Criminal Suspects in the News," Journal of Communication 49 (summer 1999): 46-60; Robert M. Entman and Andrew Rojecki, The Black Image in the White Mind: Media and Race in America (Chicago: University of Chicago Press, 2000); Kimberly A. Neuendorf, David Atkin, Leo W. Jeffres, Theresa Loszak, and Alicia Williams, "Explorations of the Simpson Trial 'Racial Divide," "Howard Journal of Communication 11 (October-December 2000): 247-66.

3. Stacey J. Lee, Unraveling The "Model Minority" Stereotype: Listening to Asian American Youth (New York: Teachers College Press, 1996); Teresa A. Mok, "Getting the Message: Media Images and Stereotypes and Their Effect on Asian Americans," Cultural Diversity and Mental Health 4 (1998): 185-202; Frank H. Wu, Yellow: Race in America Beyond Black and White (New York: Basic Books, 2002); Yuko Kawai, "Stereotyping Asian Americans: The Dialectic of the Model Minority and the Yellow Peril," Howard Journal of Communication 16 (April-June 2005): 109-30; Hye Jin Paek and Hemant Shah, "Racial Ideology, Model Minorities, and The 'Not-So-Silent Partner': Stereotyping of Asian Americans in U.S. Magazine Advertising," Howard Journal of Communication 14 (October-December 2003): 225-44.

4. Ananda Mitra, India through the Western Lens: Creating National Images in Film (Thousand Oaks, CA: Sage Publications, 1999); Srividya Ramasubramanian, "A Content Analysis of the Portrayal of India in Films Produced in the West," Howard Journal of Communication 16 (October-December 2005): 243-65.

5. Alexis S. Tan, Yuki Fujioka, and Nancy Lucht, "Native American Stereotypes, TV Portrayals, and Personal Contact," Journalism \& Mass Communication Quarterly 74 (summer 1997): 265-84; Alexis S. Tan, Yuki Fujioka, and G. Tan, "Television Use, Stereotypes of African Americans and Opinions on Affirmative Action: An Affective Model of Policy Reasoning," Communication Monographs 67 (December 2000): 362-71.

6. G. Blake Armstrong, Kimberly A. Neuendorf, and James E. Brentar, "TV Entertainment, News, and Racial Perceptions of College Students," Journal of Communication 42 (summer 1992): 153-76; Yuki Fujioka, "Television Portrayals and African-American Stereotypes: Examination of Television Effects When Direct Contact Is Lacking," Journalism \& Mass Communication Quarterly 76 (spring 1999): 52-75.

7. Patricia G. Devine, "Stereotypes and Prejudice: Their Automatic and Controlled Components," Journal of Personality and Social Psychology 56 (January 1989): 5-18; Robert S. Wyer, Jr. and Thomas K. Srull, Memory and Cognition in Its Social Context (Hillsdale, NJ: Lawrence Erlbaum, 1989); John A. Bargh, "The Cognitive Monster: A Case against the Controllability of Automatic Stereotype Effects," in Dual-Process Theories in Social Psychology, ed. Shelly Chaiken and Yaacov Trope (New York: Guilford Press, 1999). 
8. Wyer and Srull, Memory and Cognition in Its Social Context.

9. John A. Bargh, "Automatic and Conscious Processing of Social Information," in Handbook of Social Cognition, ed. Robert S. Wyer and Thomas K. Srull (Hillsdale, NJ: Lawrence Erlbaum, 1994).

10. C. Neil Macrae, Galen V. Bodenhausen, Alan B. Milne, and Jolanda Jetten, "Out of Mind but Back in Sight: Stereotypes on the Rebound," Journal of Personality and Social Psychology 67 (November 1994): 808-17.

11. Russell H. Fazio, Joni R. Jackson, Bridget C. Dunton, and Carol J. Williams, "Variability in Automatic Activation as an Unobtrusive Measure of Racial-Attitudes: A Bona-Fide Pipeline," Journal of Personality and Social Psychology 69 (December 1995): 1013-27; Russell H. Fazio and Bridget C. Dunton, "Categorization by Race: The Impact of Automatic and Controlled Components of Racial Prejudice," Journal of Experimental Social Psychology 33 (September 1997): 451-70.

12. Patricia G. Devine and Margo J. Monteith, "The Role of Discrepancy-Associated Affect in Prejudice Reduction," in Affect, Cognition, and Stereotyping: Interactive Processes in Group Perception, ed. Diane M. Mackie (San Diego, CA: Academic Press, 1993); Patricia G. Devine, "Implicit Prejudice and Stereotyping: How Automatic Are They? Introduction to the Special Section," Journal of Personality and Social Psychology 81 (November 2001): 757-59; Nilanjana Dasgupta and Anthony G. Greenwald, "On the Malleability of Automatic Attitudes: Combating Automatic Prejudice with Images of Admired and Disliked Individuals," Journal of Personality and Social Psychology 81 (November 2001): 800-14; Irene V. Blair, "Implicit Stereotypes and Prejudice," in Cognitive Social Psychology: The Princeton Symposium on the Legacy and Future of Social Cognition, ed. Gordon B. Moskowitz (Mahwah, NJ: Lawrence Erlbaum, 2001).

13. Susan T. Fiske and Steven L. Neuberg, "A Continuum of Impression Formation, from Category-Based to Individuating Processes: Influences of Information and Motivation on Attention and Interpretation," in Advances in Experimental Social Psychology, ed. Mark P. Zanna (New York: Academic Press, 1990), 1-74.

14. Daniel T. Gilbert and J. Gregory Hixon, "The Trouble of Thinking: Activation and Application of Stereotypic Beliefs," Journal of Personality and Social Psychology 60 (April 1991): 509-17.

15. Gilbert and Hixon, "The Trouble of Thinking: Activation and Application of Stereotypic Beliefs"; Fazio et al., "Variability in Automatic Activation as an Unobtrusive Measure of Racial-Attitudes: A Bona-Fide Pipeline"; Bernd Wittenbrink, Charles M. Judd, and Bernadette Park, "Evaluative Versus Conceptual Judgments in Automatic Stereotyping and Prejudice," Journal of Experimental Social Psychology 37 (April 2001): 244-52; Irene V. Blair, "The Malleability of Automatic Stereotypes and Prejudice," Personality and Social Psychology Review 6 (August 2002): 24261.

16. Christine H. Hansen and Ranald D. Hansen, "How Rock Music Videos Can Change What Is Seen When Boy Meets Girl: Priming Stereotypic Appraisal of Social Interactions," Sex Roles 19 (September 1988): 297-316; Thomas E. Ford, "Effects of Stereotypical Television 
Portrayals of African-Americans on Person Perception," Social Psychology Quarterly 60 (September 1997): 266-75; Sonja M. Brown Givens and Jennifer L. Monahan, "Priming Mammies, Jezebels, and Other Controlling Images: An Examination of the Influence of Mediated Stereotypes on Perceptions of an African American Woman," Media Psychology 7 (2005): 87-106.

17. Hansen and Hansen, "How Rock Music Videos Can Change What Is Seen When Boy Meets Girl: Priming Stereotypic Appraisal of Social Interactions."

18. Mahzarin R. Banaji, Curtis D. Hardin, and Alexander Rothman, "Implicit Stereotyping in Person Judgment," Journal of Personality and Social Psychology 65 (August 1993): 272-81; Blair, "The Malleability of Automatic Stereotypes and Prejudice"; Wittenbrink, Judd, and Park, "Evaluative Versus Conceptual Judgments in Automatic Stereotyping and Prejudice"; Bargh, "Automatic and Conscious Processing of Social Information."

19. Givens and Monahan, "Priming Mammies, Jezebels, and Other Controlling Images: An Examination of the Influence of Mediated Stereotypes on Perceptions of an African American Woman."

20. Dorothy G. Singer and Jerome L. Singer, "Learning How to Be Intelligent Consumers of Television," in Learning from Television: Psychological and Educational Research, ed. M.J.A. Howe (London: Academic Press, 1983); James A. Brown, Television Critical Viewing Skills Education: Major Media Literacy Projects in the United States and Selected Countries (Hillsdale, NJ: Erlbaum, 1991); Art Silverblatt, Media Literacy: Keys to Interpreting Media Messages (Westport, CT: Praeger, 1995); E. Thoman, "Media Literacy Education Can Address the Problem of Media Violence," in Media Violence: Opposing Viewpoints, ed. B. Leone (San Diego, CA: Greenhaven Press, 1999); Renee Hobbs, "The Great Debates Circa 2001: The Promise and the Potential of Media Literacy," Community Media Review 21 (spring 2001): 17-23.

21. Erica Scharrer, "Making a Case for Media Literacy in the Curriculum: Outcomes and Assessment," Journal of Adolescent $\mathcal{E}$ Adult Literacy 46 (December-January 2002): 2-6.

22. James A. Anderson, "Television Literacy and the Critical Viewer," in Children's Understanding of Television: Research on Children's Attention and Comprehension, ed. J. Bryant and D.R. Anderson (New York: Academic Press, 1983), 297-330; James A. Brown, "Media Literacy Perspectives," Journal of Communication 48 (1998): 44-57; Joanne R. Cantor, "Media Violence," Journal of Adolescent Health 27 (2000): 30-40; Hobbs, "The Great Debates Circa 2001: The Promise and the Potential of Media Literacy."

23. Susan T. Fiske, Monica Lin, and Steven L. Neuberg, "The Continuum Model: Ten Years Later," in Dual Process Theories in Social Psychology, ed. Shelly Chaiken and Yaacov Trope (New York, NY: Guilford Press, 1999).

24. Amy I. Nathanson, "Identifying and Explaining the Relationship between Parental Mediation and Children's Aggression," Communication Research 26 (April 1999): 124-43; Amy I. Nathanson and 
Mong-shan Yang, "The Effects of Mediation Content and Form on Children's Responses to Violent Television," Human Communication Research 29 (January 2003): 111-34; Kerry Kawakami, John F. Dovidio, Jasper Moll, Sander Hermsen, and Abby Russin, "Just Say No (to Stereotyping): Effects of Training in the Negation of Stereotypic Associations on Stereotype Activation," Journal of Personality and Social Psychology 78 (May 2000): 871-88; Johannes W. J. Beentjes, Marianne van Oordt, and Tom H. A. van der Voort, "How Television Commentary Affects Children's Judgments on Soccer Fouls," Communication Research 29 (2002): 31-45.

25. Kawakami et al., "Just Say No (to Stereotyping): Effects of Training in the Negation of Stereotypic Associations on Stereotype Activation."

26. David J. Schneider, The Psychology of Stereotyping (New York: Guilford, 2004).

27. Galen V. Bodenhausen, Norbert Schwarz, Herbert Bless, and Michaela Waenke, "Effects of Atypical Exemplars on Racial Beliefs: Enlightened Racism or Generalized Appraisals?" Journal of Experimental Social Psychology 31 (1995): 48-63; Dasgupta and Greenwald, "On the Malleability of Automatic Attitudes: Combating Automatic Prejudice with Images of Admired and Disliked Individuals."

28. J. Gerard Power, Sheila T. Murphy, and Gail Coover, "Priming Prejudice: How Stereotypes and Counter-Stereotypes Influence Attribution of Responsibility and Credibility among Ingroups and Outgroups," Human Communication Research 23 (September 1996); Mark Peffley, Jon Hurwitz, and Paul M. Sniderman, "Racial Stereotypes and Whites' Political Views of Blacks in the Context of Welfare and Crime," American Journal of Political Science 41, (January 1997): 30-60.

29. Wittenbrink, Judd, and Park, "Evaluative Versus Conceptual Judgments in Automatic Stereotyping and Prejudice"; Lorella Lepore and R. Brown, "Category and Stereotype Activation: Is Prejudice Inevitable?" Journal of Personality and Social Psychology 72 (February 1997): 275-87.

30. Devine, "Stereotypes and Prejudice: Their Automatic and Controlled Components."

31. Fiske and Neuberg, "A Continuum of Impression Formation, from Category-Based to Individuating Processes: Influences of Information and Motivation on Attention and Interpretation."

32. Patricia G. Devine and Margot J. Monteith, "Automaticity and Control in Stereotyping," in Dual-Process Theories in Social Psychology, ed. Shelly Chaiken and Yaacov Trope (New York: Guilford Press., 1999).

33. Fazio et al., "Variability in Automatic Activation as an Unobtrusive Measure of Racial-Attitudes: A Bona-Fide Pipeline."

34. Peter Glick and Susan T. Fiske, "The Ambivalent Sexism Inventory: Differentiating Hostile and Benevolent Sexism," Journal of Personality and Social Psychology 70 (March 1996): 491-512.

35. Janet K. Swim and Charles Stangor, eds., Prejudice: The Target's Perspective (San Diego, CA: Academic Press, Inc, 1998). 